\title{
LIXO REVIRADO: UMA ANÁLISE DA PERCEPÇÃO DOS AGENTES PÚBLICOS MUNICIPAIS DA GOVERNANÇA DO LIXO
}

\author{
TURNED GARBAGE: AN ANALYSIS OF THE PERCEPTION OF \\ MUNICIPAL PUBLIC AGENTS OF WASTE GOVERNANCE
}

Zenóbio José Azevedo Maia ${ }^{1}$ Thaynara Martins Silva Barreto ${ }^{2}$ Stephanie Ingrid Souza Barboza ${ }^{3}$

Erielem Araújo Nasciemento ${ }^{4}$

Graduando em

Administração pela Universidade Federal da Paraíba

Graduada em administração pela Universidade Federal da Paraíba 3

Professora Adjunta da Universidade Federal da Paraíba - Campus III, atuante na graduação em Administração no CCHSA/ UFPB e no Programa de Pós-graduação em Gestão Pública e Cooperação Internacional (PGPCI/CCSA/ UFPB). Atualmente é vicecoordenadora do PGPCI, além de liderar o Núcleo de Estudos em Marketing no Interesse Social (MIS) e editorar o periódico Métodos de Pesquisa em Administração (MEPAD). 4

Pós graduanda em gestão pública e cooperação internacional e graduada em Administração pela Universidade federal da Paraíba (UFPB), atualmente participa como pesquisadora do Núcleo de Estudos em Marketing no Interesse Social (MIS) no qual realiza estudos que permeiam a gestão pública e sociedade com abordagens do marketing social.
RESUMO: Os problemas de gerenciamento dos resíduos sólidos extrapolam a coleta, ao alcançar a responsabilização do agente público, titular ou concessionário, no descarte ou reaproveitamento do lixo. Dessa forma, este estudo objetivou identificar os desafios, na percepção dos agentes públicos, para a governança do lixo e a instalação de aterros sanitários. Para isto, foram estudadas cidades paraibanas que se encontram no processo de instalação e gerenciamento do aterro sanitário, sendo entrevistados 12 agentes públicos do executivo municipal, abordando aspectos sobre governança do lixo e o processo de implantação e gestão do aterro sanitário. Por fim, os resultados apontam para o desafio das instalações e manutenção dos aterros sanitários dos seis municípios estudados, que são decorrentes de três fatores principais: a descontinuidade política, a escassez de recursos e a falta de colaboração da população, o que fornece um panorama da situação e aponta para os problemas que devem ser sanados para implementação eficiente dos aterros sanitários.

PALAVRAS-CHAVE: governança do lixo; aterro sanitário; agentes públicos.

ABSTRACT: The problems of solid waste management go beyond the collection, when reaching the responsibility of the public agent, holder or concessionaire, in the disposal or reuse of waste. Thus, this study aimed to identify the challenges, in the perception of public agents, for the governance of waste and the installation of landfills. For this, cities in Paraíba that are in the process of installation and management of the landfill were studied, being interviewed 12 public agents of the municipal executive, addressing aspects of garbage governance and the process of implantation and management of the landfill. Finally, the results point to the challenge of installing and maintaining landfills in the six municipalities studied, which are due to three main factors: political discontinuity, the scarcity of resources and the lack of collaboration by the population, which provides an overview situation and points out the problems that must be solved for the efficient implementation of landfills.

KEYWORDs: waste management; landfill; public agents. 


\section{INTRODUÇÃO}

É reconhecido que os problemas de gerenciamento dos resíduos sólidos extrapolam a coleta, ao abranger nesse processo desde a geração do resíduo até a responsabilização do agente público, titular ou concessionário, no descarte ou reaproveitamento do lixo. No Brasil, o processo de gerenciamento do lixo é norteado pelo direcionamento do governo federal, em estabelecer a nível local ou municipal as funções de coleta e tratamento dos resíduos (MAIELLO, BRITTO, VALLE, 2018). Conforme apontam dados da Pesquisa Nacional de Saneamento Básico (BRASIL, 2010), o manejo dos resíduos sólidos é realizado em sua maioria pelos municípios, correspondendo a 59,1\% dos serviços prestados e $31,2 \%$ dos municípios executam os serviços em parceria com outras entidades.

Em essência, as reformas promovidas nos aspectos de governança de resíduos nos níveis federal, estadual e municipal, estabeleceram funções determinantes para os municípios por meio da Política Nacional de Resíduos Sólidos (PNRS) (MAIELLO et al., 2018). O atual marco legal se dá pela Lei no 12.305/2010 que definiu a responsabilidade de realizar procedimentos operacionais de serviços públicos de limpeza urbana e de manejo de resíduos sólidos, incluindo a disposição final ambientalmente adequada dos rejeito, aos municípios, exigindo a substituição de lixões a céu aberto por aterros sanitários como medida de proteção sanitária e ambiental. No entanto, existe uma série de questões que afetam a gestão municipal do lixo, como apontado por Krasniqui, Krasniqui e Krasniqui (2013), tais como a legislação incompleta, o baixo nível de consciência institucional e pública, a falta de informação técnica sobre produção e composição dos resíduos, além dos elevados custos de manutenção das instalações de tratamento e manejo dos resíduos.

A extinção dos chamados "lixões" deveria ter ocorrido em meados de 2014, entretanto os novos prazos remetem aos anos de 2018 e 2021. A procrastinação desse serviço público evidencia a necessidade de discussão sobre os aspectos de governança que permeiam os atores centrais: o Estado, a sociedade e as empresas. As questões supracitadas tornam proeminente a discussão sobre o papel dos stakeholders envolvidos na geração e nos aspectos de governança no processo de gerenciamento do lixo. Muitos estudos foram desenvolvidos acerca da governança do lixo (EZEAH; ROBERTS, 2014; OWUSU, OTENGABABIO, AFUTU-KOTEY, 2012; HOWELL, 2017), com o foco prioritário na infraestrutura para o tratamento do lixo, como no caso dos aterros sanitários. No caso desse estudo, o objetivo é identificar a percepção dos agentes públicos municipais na governança do lixo e o processo de instalação do aterro sanitário.

Para o desenvolvimento dessa pesquisa são apresentados, inicialmente, uma breve exposição sobre a governança do lixo e o caso dos aterros sanitários. Em seguida, são exibidos os procedimentos me- 
todológicos adotados na coleta e análise de dados por meio de entrevistas dos agentes públicos municipais envolvidos na governança do lixo. Por fim, são apresentados os resultados observados na pesquisa e as considerações finais.

\section{GOVERNANÇA DO LIXO}

As discussões sobre governança permeiam aspectos relativos ao desempenho do Estado no gerenciamento das relações entre os mais diversos atores que o circundam, perpassam agentes públicos e privados, estruturas formais, regulações e práticas de controle (ROY, 2006). Por sua vez, a governança pública assume o caráter de um sistema social mais amplo de gestão, contrapondo a perspectiva de que o Estado deve ser o único tomador de decisão no contexto público (HENN, et al; 2017).

Conforme apontam Kissler e Heidmann (2006), a governança debate a inclusão de todos os agentes no processo decisório, na medida em que pressupõe a negociação, a comunicação e a confiança como elementos norteadores da ação pública. No que diz respeito aos recursos, Hall (2002) ainda coloca que um modelo de governança eficaz precisa se basear nesses preceitos para atuar como um sistema aberto para a participação da sociedade civil, das empresas privadas e dos meios de comunicação. Em um debate de governança global, Finkelstein (1991), afirma que os estudos acerca da governança estão preocupados não apenas com decisões, mas também com consequências e seus efeitos distributivos, programas e projetos, eficácia, consentimento, e implementação doméstica.

Em uma perspectiva moderna, o debate de governança superaria essa discussão mais processual de inclusão dos agentes, ao partir do entendimento de que seu conceito abarca uma hibridez ocasionada pelo alto nível de interlocução entre as diversas formas organizacionais público-privada e suas redes (LINDQVIST, 2013). Frey (2004) destaca que a governança exige interação entre os diversos atores sociais e o Estado, pressupondo a construção de parcerias que envolvam atores não estatais participes das decisões e da provisão dos serviços públicos. Desse modo, o caráter híbrido da governança favoreceria a incorporação de condições de cooperação no exercício da responsabilidade pública pela provisão de serviços, em nível local, incluiria políticas, instrumentos políticos, normas e contratos, implicando numa interação tanto discursiva quanto material. No sentido prático, isso se observa facilmente nas parcerias público-privadas destinadas para o gerenciamento do lixo (LIMA; FILHO, 2017).

No debate de governança é preciso refletir sobre a estrutura de poder político e as regras que conduzem a forma de cooperação e de competição dos agentes que atuam em determinado contexto. Nesse sentido, a Organização das Nações Unidas (ONU, 2009) indica como princípios para boa governança a promoção da igualdade, a participação, o pluralismo, a transparência, a responsabilidade e o Estado de direito, de maneira efetiva, eficiente e duradoura. E suas principais 
ameaças vem da corrupção, da violência e da pobreza que geram prejuízos a transparência, a segurança, a participação da população e suas liberdades fundamentais.

De maneira geral, a prestação dos serviços públicos em torno do gerenciamento do lixo é precária, muitos municípios relatam que os problemas relacionados à governança decorrem da incapacidade sistêmica por parte de atores estatais para sancionar ou lidar com os mais diversos stakeholders envolvidos (KRASNIQUI ET AL.; 2013). De fato, a autoridade municipal muitas vezes não tem experiência, conhecimento e recursos necessários para desenvolver um plano municipal de resíduos sólidos e, por outro lado, a sociedade não é consciente da importância do seu papel em manter a cidade limpa, descartando de forma adequada e mantendo as taxas desatualizadas.

Objetivamente, a gestão de resíduos não pode ser realizada apenas por um agente, são necessárias ações conjuntas da sociedade, do legislativo, do executivo, dos órgãos reguladores, das empresas de coleta de resíduos e de gerenciamento de aterros. Os resíduos têm destino final regulado, mas muitos municípios brasileiros atuam de forma diferente do que propõe a legislação. Atualmente, no país, é comum que os resíduos sejam descartados de forma inadequada, o que impacta sobremaneira nas condições ambientais e de saúde da cidade (NARUO, 2003; LIMA et al., 2017). É fato comum, em momentos de dificuldades na gestão pública municipal que o lixo não seja regularmente coletado, permanecendo junto às habitações (principalmente em áreas de periferia), ou sendo vazada em logradouros públicos, terrenos baldios, encostas e cursos d'água (MONTEIRO, et al., 2001).

Referente aos riscos com o descarte inadequados de lixo, o gerenciamento dessa questão sempre foi um desafio para os gestores municipais, principalmente para cidades de pequeno porte que, muitas vezes, não contam com profissionais capacitados nos órgãos públicos, dificultando assim a tomada de decisão acerca da sustentabilidade do sistema de gestão de resíduos da maioria dos municípios no Brasil (LIMA et al., 2017; MONTEIRO et al., 2001). A gestão de resíduos sólidos está relacionada diretamente as decisões estratégicas ligadas aos aspectos institucionais, administrativos, financeiros e operacionais dos órgãos municipais, sendo considerado um conjunto de procedimentos com finalidade de buscar uma solução viável e eficiente para descarte dos resíduos sólidos que não tenham impactos na saúde pública nem no meio ambiente (MONTEIRO et al., 2001; LIMA et al., 2017).

Há uma tendência de preocupação da população em torno da gestão do lixo que permeia, prioritariamente, a coleta em detrimento da destinação final. Disso decorre a tentativa de economizar recursos com a destinação, já que muitas vezes a fiscalização dos procedimentos de destino final normalmente é ineficiente. Tal preocupação é passível de compreensão, na medida em que, a coleta seletiva no Brasil não foi criada por meio de políticas e diretrizes públicas, mas sim a partir da movimentação local, na maioria das vezes de origem filantrópica, eco- 
nômica ou ecológica (OLIVEIRA, 2002).

Apesar de haver um debate proeminente sobre a destinação do lixo nos últimos anos (JACCOUD, MAGRINI, 2014; WALDNAN, 2013; FORÉS-IBÁÑEZ, et al., 2017), a solução para o descarte, em várias cidades no Brasil, ainda é leva-lo para locais afastados de áreas habitadas, a céu aberto - os lixões - situados na periferia dos grandes centros ou em zonas rurais em municípios de menor porte (GAZZINELLI et al., 2001). Convencionalmente, o descarte dos resíduos sólidos se resume a um conjunto de procedimentos destinados a reduzir a quantidade ou o potencial poluidor dos resíduos sólidos, seja impedindo o descarte do lixo em ambiente ou local inadequado, transformando-o em material inerte ou biologicamente estável.

Entre as formas de disposição para descarte de resíduos sólidos no Brasil, conta-se com algumas opções, como: o lixão que é a forma mais inadequada de disposição final de resíduos; os aterros controlados, cuja técnica que se baseia na disposição de resíduos sólidos no solo cobrindo-os com uma camada de material inerte, sem causar danos e com impacto ambiental minimizado; e os aterros sanitários (NARUO, 2003; ABNT, 1983; MONTEIRO et al., 2001). O aterro sanitário é a prática atual mais eficiente, em termos técnicos, reduz o volume dos resíduos e faz uso da menor área possível, além de drenar os líquidos e os gases gerados pelo lixo (HIRD et al., 2014, ABNT, 1983; LIMA et al., 2017).

Além de minimizar os impactos ambientais adversos, os aterros sanitários ajudam a evitar danos ou riscos à saúde pública e à segurança (RAMOS, 2014). Dito isto, é preciso um olhar mais atencioso dos gestores públicos brasileiros, quando se trata do descarte de resíduos sólidos. Para a implementação de aterros sanitários, há normas delimitadas pela Associação Brasileira de Normas e Técnicas (ABNT), sendo a principal a NBR 8419 de 1983, que descreve as diretrizes e técnicas dos elementos essenciais aos projetos de aterros desde o começo do processo de implementação (ABNT, 1983).

\section{O CASO DOS ATERROS SANITÁRIOS BRASILEIROS}

O lixo produzido no Brasil representa um problema relevante devido à quantidade e à diversidade, que requer um conjunto integrado de práticas previstas nos requisitos legais (OLIVEIRA, 2013). Existe uma exigência federal para a execução dos aterros sanitários, como se dá na Lei $\mathrm{n}^{\mathrm{o}}$ 12.305/2010, para o fim dos lixões. O art. 54 do PNRS estabelece que "a disposição final ambientalmente adequada dos rejeitos, observado o disposto no $\S 1$ 1o do art. 9o, deverá ser implantada em até quatro anos após a data de publicação desta Lei".

O prazo legal para o fim dos lixões foi até 2014 e um início tardio do tratamento dos resíduos no Brasil começaria, mas já se passaram alguns anos e a implantação dos aterros sanitários em todos os municípios brasileiros não foram alcançados, nem tampouco a conscientização com relação a separação do lixo e a inclusão dos catadores na provisão desse serviço público. De acordo com a Associação Brasileira 
de Empresas de Limpeza Pública e Resíduos Especiais (ABRELPE) no ano de 2016, 60\% dos municípios brasileiros apresentaram disposição final ambientalmente inadequada, apenas 2.239 utilizavam o aterro sanitário para a disposição final. Com o atraso da execução desses aterros, surge um novo Projeto de Lei no 2.289/2015 no Senado Federal, alterando a Lei de Resíduos Sólidos (especificamente no que trata o art. 54 da Lei no 12.305 , de 2 de agosto de 2010) e estendendo a data-limite para o fim dos lixões e para a disposição final dos resíduos ambientalmente adequada.

Um dos métodos utilizados como solução para instalação das unidades operacionais dos aterros está sendo o consórcio estabelecido através de uma relação entre os municípios, de modo que aqueles que possuem áreas maiores e mais adequadas se consorciam com cidades vizinhas para receber os seus resíduos. Com isso, os governos federais e estaduais têm aplicado mais recursos e criado programas e linhas de crédito em que os beneficiários são os municípios envolvidos no acordo, potencializando a solução dos problemas do gerenciamento do lixo e a manutenção de sua qualidade ao longo do tempo (MONTEIRO, 2001).

O avanço lento no processo de adequação da destinação do lixo no Brasil repercute negativamente, na medida em que outras regiões do mundo a gestão do lixo assume um papel fundamental na redução do impacto ambiental e social. Como por exemplo, a China em 2006 produziu 120 milhões de toneladas de lixo, enquanto em 2010 contabilizou 148 toneladas, sendo que 91,4\% do lixo foram reciclados, 6,4\% incinerado e apenas 2,2\% descartado para aterros sanitários. Na União Europeia, a gestão do lixo não se resume entre reciclagem e descarte, a discussão atual diz respeito à transformação do descarte de lixo em energia, para contribuir para a economia circular e consequentemente manter o valor de produtos, materiais e recursos no mercado, minimizando os desperdícios (ZHANG, et al., 2010; MALINAUSKAITE, et al., 2017).

Mais especificamente, há na Alemanha uma das maiores taxas de reciclagem da Europa e também uma extração significativa de energia dos resíduos através da combustão de massa. Em 2006, a Alemanha reciclava $60 \%$ do lixo, 30\% eram usados para gerar energia enquanto apenas 1\% era descartado para aterro sanitário (MÜHLE, et al., 2010). Enquanto o Reino Unido ainda depende do aterro sanitário, porém a reciclagem vem aumentando nos últimos anos. Tais dados apontam um caminho para o Brasil, que busca avançar, porém encontra entraves devido aos problemas de gestão dos municípios e de interlocução entre os atores interessados no gerenciamento adequado dos resíduos.

De fato, essas dificuldades vêm sendo observadas com maior rigor pela população, pelos órgãos de controle ambiental, pelo Ministério Público e pelas organizações não-governamentais voltadas para a defesa do meio ambiente (MONTEIRO et al., 2001), porém qualquer aplicação de recurso que busque tornar eficiente o gerenciamento do lixo 
ainda é tratado como uma despesa subvalorizada pela maioria dos gestores públicos municipais. De todo modo, o desafio da governança do lixo não se resume apenas ao financiamento da coleta, da destinação e do tratamento do lixo no Brasil, é preciso também reduzir a geração de lixo através de um processo de conscientização dos stakeholders acerca do que é uma boa gestão integrada do lixo.

\section{PROCEDIMENTOS METODOLÓgICOS}

Esta pesquisa se caracteriza por ser de natureza qualitativa e caráter exploratório (CHAVES, BATALHA, 2006; GODOY, 2006). No caso desse estudo, o debate central parte da análise da percepção e da interlocução dos agentes públicos municipais na governança do lixo, sendo envolvidos nessa pesquisa os municípios do interior paraibano: Campina Grande, Alagoa Grande, Dona Inês, Guarabira, Solânea e Bananeiras.

São estudadas cidades com diferentes perfis econômicos e sociodemográficos, Campina Grande é a maior cidade, possui cerca de 386 mil habitantes e já desenvolve a destinação no aterro sanitário através de uma parceria público-privada, tornando-se referência para a região. A cidade de Alagoa Grande possui 28.479 habitantes, e foi a primeira cidade do estado a refletir sobre a possibilidade de construção do aterro sanitário e a iniciar seu processo de construção em meados de 2008. O município de Dona Inês com 10.517 habitantes teve as instalações do aterro sanitário iniciadas dentro das regulamentações exigidas, porém, a obra se mantém parada. Já os municípios de Solânea (26.693 habitantes), Bananeiras (21.851 habitantes) e Guarabira (55.326 habitantes) fazem parte de um conjunto de cidades que busca a construção de um aterro sanitário para suprir suas necessidades de descarte de lixo por meio de um consórcio (IBGE, 2010).

A coleta dos dados ocorreu através de entrevistas realizadas presencialmente com roteiro semiestruturado, a fim de compreender a visão e ações dos agentes públicos acerca do tratamento e destinação do lixo e como o caso do aterro sanitário estava sendo conduzido. Para tanto, foram entrevistados 12 agentes públicos do executivo municipal, para fins de organização e análise foram nomeados conforme a ordem de entrevista. As entrevistas foram realizadas no período de setembro e dezembro de 2017, as quais foram gravadas em áudio e posteriormente transcritas. Ao final, foi obtido um total de 09 horas, 19 minutos e 56 segundos de entrevista e um total de 194 laudas de transcrição em Word, fonte Times, tamanho 12, espaçamento 1,5.

Os dados foram tratados pelo método de análise de conteúdo, que tem como propósito a descrição e interpretação dos conteúdos de documentos e textos, de modo que foi procedida uma análise categorial para identificação e classificação de palavras-chave e argumentos relacionados (MORAES, 1999; BARDIN, 2007). Para isso foram abordadas duas dimensões e suas respectivas subdimensões. A primeira dimensão foi a Governança do Lixo e a segunda Aterro Sanitário. 


\section{GOVERNANÇA DO LIXO: A GESTÃO PÚBLICA MUNICIPAL E A DESCONTINUIDADE POLÍTICA}

"Nossa realidade hoje é uma caçamba, nós temos aqui cinco coletores na nossa realidade, são cinco caçambas, cada uma com seis servidores, dois em cima e quatro embaixo, recolhendo lixo e arrumando. Quando assumimos, procuramos colocar pelo menos redes e o EPA, material de proteção do pessoal, máscaras, alguns preferem usar, outros nem querem usar. Então, ainda é um sistema rudimentar, isso aí não é o correto. " (AP12)

O Governo Brasileiro definiu, por meio da lei $\mathrm{n}^{\circ} 12.305$, de 2 de agosto de 2010, que os lixões deveriam acabar. Em 1981 foi criada a $1^{\circ}$ Política de Meio Ambiente (Lei N 6.938, de 31 de agosto de 1981), que definiu que o lixo e os processos municipais adotados pelos agentes públicos eram fontes de poluição e deveriam ter sido substituídas por aterros sanitários e por ações complementares como a coleta seletiva e a reciclagem. Mais de quinze anos depois foi criada a lei (Lei ${ }^{\circ} 9.604$ de 12 de fevereiro de 1998) que tipificou os lixões como crime ambiental, no entanto o relato acima torna evidente a lacuna entre a capacidade de execução dos municípios e a regulação. No que diz respeito a essa baixa capacidade de adaptação dos municípios as exigências para as novas práticas de gestão do lixo, os agentes públicos refletiram sobre a realidade do lixo como ilustra a fala do Agente Público 1.

“... Ninguém nem pensava em lixo, nem em fazer aterro, não tinha aquela pressão do poder público, do Ministério Público, nem nenhuma lei federal que regulamentasse e exigindo que fizesse logo... depois veio... E estão adiando, adiando, adiando e um dia vai ter que ser resolvido. " (AP1).

Considerando que se passaram quase quatro décadas desde a definição da política de meio ambiente, é possível afirmar que a realidade da destinação do lixo no Brasil ainda precisa de avanços. Entre as 5,5 mil cidades do Brasil, se somados aos aterros controlados, são quase $60 \%$ dos munícipios com descarte inadequado do lixo (ABRELPE, 2015). Como dito, os lixões deveriam ter fechado em 31 de julho de 2014, entretanto, o Congresso aprovou uma emenda que prorroga o prazo para até em 2021 no caso das cidades com menos de 50 mil habitantes, para as cidades de 50 a 100 mil habitantes para 2020, com mais de 100 mil habitantes para 2019 e para as capitais e regiões metropolitanas, o prazo final ficou para 2018. O Plano Nacional de Resíduos Sólidos (PNRS) prevê responsabilizações no não cumprimento desse prazo, deixando claro que a omissão, por parte dos agentes públicos, pode resultar em sanções administrativas e penais.

Com as condições para a exigência do PNRS, há a discussão sobre quais são os atores responsáveis pelo não cumprimento da lei, visto que por um lado os municípios criam seus próprios empasses para o não cumprimento, enquanto outro se visualiza que os municípios não tinham a mínima chance de cumprir a lei, pela falta de estrutura dos 
mesmos e por outros aspectos políticos. Essa visão sobre a falta de recursos foi compreendida na fala do Agente Público 7:

\begin{abstract}
"As dificuldades políticas são os maiores entraves porque vamos supor, tem um município aqui que é muito perto desse, né!? Mas são adversários políticos, aí eles já não se entendem ter condição de ter um aterro comum, né!? Então eu considero a descontinuidade politica um dos maiores problemas e grave mesmo, porque nós temos aí quatro anos alguém que está trabalhando com um determinado pensamento, pode ter até boa vontade, tenha conhecimento técnico ou não, mas pode ter boa vontade e designa a gestão nessa direção. Aí entra outro do partido adverso e diz: não, eu não vou fazer o que fulano fez, primeiro por que ele é meu inimigo e segundo eu vou fazer isso aqui e vão atribuir que foi ele, eu não quero, eu quero os louvores para mim, né!? E daí vai, e o que que acontece, muitas vezes eles deletam até planilhas históricas que servem como base de dados para planejamento. Aí eles destroem, os HD são retirados dos computadores, os dados são destruídos e a questão dos resíduos sólidos a solução é uma solução de longo prazo, né!? Que historicamente está tudo errado, né!? Então, a gente não vai resolver isso assim numa gestão só, né!? Precisa é muito tempo e muita gente trabalhando para gente tentar melhorar pouco a pouco cada uma das... " (AP7)
\end{abstract}

A gestão do lixo é um problema público complexo e precisa da conexão entre entidades governamentais, diversos entraves têm influenciado na governança do lixo como um todo. Um dos problemas apontados diz respeito a troca de gestão, tendo em vista que a manutenção de qualquer projeto se torna mais difícil com as barreiras partidárias entre os gestores. Segundo Estevam (2010) esse problema é mais visível nas cidades de médio e pequeno porte, principalmente quando não acontece a manutenção do mesmo grupo político-partidário no poder, isso comumente suscita dúvida na continuidade das políticas desenvolvidas anteriormente. Um dos agentes públicos reconhece que mesmo que o gestor entenda que as questões envolvendo o lixo devam ser tratadas além da perspectiva ambiental, é preciso que a gestão subsequente desenvolva um espírito de preservação da ação pública como também uma consciência ambiental.

"Isso (a implementação dos aterros) é a dor de cabeça do gestor, porque de gestor para gestor muda. E o grande problema de qualquer política é a descontinuidade delas" (AP2).

"Tem que ter dos gestores, ele tem que ter uma consciência ambiental que venha favorecer, não venha vamos supor, não é porque fulano começou, tal gestão começou e eu não vou dar continuidade, não, ele tem por obrigação dar continuidade ao serviço de preservação. " (AP12)

Como forma de suplantar tal dificuldade, a cidade de Campina Grande, já compreende que há a necessidade de quando tratar da elaboração de projetos maiores e de alto impacto social, consolidar o 
projeto na construção de um plano diretor, cujo papel é nortear um planejamento da cidade para uma década, com prazos e projetos a executar e manter.

"A gente conversou com o tribunal (sobre o plano diretor) e eles também usaram na prestação de contas, e foi criado um comitê gestor dentro da federação das indústrias que vai ter a função de monitorar, para ver se o gestor está cumprindo, para cobrar o que está nele. " (AP8).

A descontinuidade política tem motivos partidários, mas é recorrente, devido à falta de interesse da sociedade em exigir a perpetuação das soluções para os problemas públicos. De acordo com o levantamento do IBGE em 2010, Campina Grande demonstrou que entre os habitantes maiores de 15 anos, 56.41\% deles possuem escolaridade no $2^{\circ}$ Ciclo do Ensino Fundamental ( $6^{\circ}$ ao $9^{\circ}$ ano), pouco acima da média nacional de $54.63 \%$. Enquanto a cidade de Dona Inês apresentou que apenas $28,04 \%$ da sua população o mesmo nível de escolaridade. Um maior nível de escolaridade muitas vezes é associado com um maior desenvolvimento profissional e com um maior interesse em questões sociais, públicas e reivindicação desses direitos. É muito comum encontrar movimentos sociais e cidadãos recorrendo por soluções de problemas públicos em grandes centros do que em cidades de pequeno porte.

De maneira geral, a baixa escolaridade e o pouco entendimento sobre os problemas públicos influenciam na capacidade de interlocução da sociedade com os governantes. É de fácil entendimento que a cooperação entre sociedade e gestores públicos é a melhor saída para a solução de problemas da comunidade, entretanto, conforme relatado pelo Agente Público 1, a participação da população na governança do lixo é insuficiente ou nula.

"Essa questão do gestor, gestor tem que ter atitude, sabendo que vai ter polêmica... Às vezes, você abre a discussão e ninguém vai. Quando começa a fazer, aparece alguém falando 'Ah, mas você não discutiu com a sociedade! '... O povo não vai [...] quando vai, na visão que eles têm é que vai resolver tudo que eles querem, aí 'Ah, isso não vai dar em nada não, já prometeram e não saiu'... Eles acham que se eles forem lá e pedir, vai ter que sair. Cidade maior não, as pessoas têm uma visão maior a nível de estado..." (AP1)

Para o cidadão comum, o lixo só se torna um problema quando há interrupção na coleta, caso o lixo não se amontoe nas calçadas, não polua a porta da casa do cidadão, continua sendo assunto ignorado. Isso evidencia a miopia dos cidadãos com relação ao tratamento e destinação do lixo, uma vez que é encarado mais como um problema do poder público que tem que retira-lo e leva-lo. Tal fato é evidenciado na fala de um dos agentes.

"Falando, francamente, a população não dá muito olhos à ques- 
tão do resíduo. 'Ficando escondido de mim, eu não quero saber', muita gente pensa assim. Pelo menos é o que eu escuto. É, saiu da minha porta, não tenho interesse. " (AP1)

Com a ausência de interesse da sociedade em solicitar as soluções para os problemas públicos, é comum que, na realidade do Brasil, os gestores atuam com o foco em outros interesses. A gestão do lixo pode ser um exemplo desse aspecto devido à falta de interesse por parte da população de exigir as soluções para tal problema, os gestores transferindo a responsabilidade para outras entidades, como os catadores de lixo e empresas recicladoras.

"Então, lá no lixão ninguém estava vendo e ninguém conhece quais são os danos, só a população que está lá no final que são os catadores de resíduos que vivem numa situação degradante, que já é outro tipo de problema... é muito fácil você vir com um caminhão e colocar do jeito que quer, como quer, onde quer. Então se você compara com o que a lei quer, o lixo fica caro, por isso que os políticos muitas vezes não querem investir no destino final, porque ele diz é caro e não dá voto, porque ninguém ver, né!? Porque ninguém vê." (AP7)

Outro fator que contribui para que problemas como o lixo seja resolvido, é a corrupção na esfera pública, tendo em vista que muitas vezes o agente público executa conscientemente suas atividades visando o benefício próprio ou favorecimento de terceiros, desconsiderando os princípios que regem a Administração Pública e a governança. Portanto, uma das consequências dessas ações envolvendo corrupção por partes dos agentes públicos é a diminuição da qualidade de vida da população como um todo, demandando uma enorme necessidade de mecanismos eficientes que controlem as atividades públicas. Isso corrobora com a visão da ONU que aponta a corrupção como uma ameaça para boa governança.

O processo de descarte do lixo nas cidades estudadas tem sido dificultado também devido a um sistema ineficaz de coleta adotado pelos municípios, o qual não adota a separação por tipo de lixo, refletindo posteriormente na disposição final do lixo, geralmente descartado em terrenos baldios ou áreas periféricas, o que vai de encontro aos estudos de (MONTEIRO et al., 2001). Esse descarte inadequado realizado pela maioria das gestões municipais brasileiras é uma forma de utilizar pouco recurso com a destinação final do lixo, já que praticamente não há fiscalização, o que é compreensível segundo (OLIVEIRA, 2002), na medida em que, a coleta seletiva não foi criada através de políticas públicas e sim através movimentos locais filantrópicos, econômicos e ecológicos. 


\section{O ATERRO SANITÁRIO}

"O aterro é visto como um vilão, ele é tido como vilão quando te aterra tudo e retira outras oportunidades de tratar os resíduos que não sejam simplesmente aterrar, né? ... mas essa técnica ela é a mais empregada no mundo inteiro, por que? Porque existe uma praticidade e é baixo custo quando se compara a outras tecnologias, como a reciclagem, a compostagem, a incineração etc. Então, é barato quando a gente compara com essas outras técnicas, porém é caro quando a gente compara com a forma inadequada que é lixão. " (AP7)

Os aterros sanitários são definidos como técnica de disposição de resíduos sólidos urbanos no solo, sem causar danos à saúde pública, minimizando os impactos ambientais, sendo utilizados os princípios de engenharia para confinar os resíduos e rejeitos a menor área possível, reduzindo ao menor volume permissível, cobrindo-o com uma camada da terra (ABRELPE, 2015). Devido às demandas do aterro, muitos municípios pequenos não conseguem desenvolver potencial técnico, $\mathrm{o}$ que os direciona a adotar o consórcio intermunicipal como uma modalidade viável para a gestão do lixo. O agente público 10 reconhece a influência da descontinuidade política no desenvolvimento do consórcio, tendo em vista que a renovação nos quadros de gestão dos municípios demanda reajustes nos acordos do consórcio.

"O interesse no consórcio surgiu porque o prefeito como já foi deputado, pensa também naqueles municípios circunvizinhos, ele não quer deixar os outros municípios prejudicados no sentido de que, tem um município vizinho nosso aqui com 6.000 habitantes, o município lá não tem condições nem de construir e nem gerenciar um aterro sanitário. ” (AP10)

"Na verdade, a gente teve uma certa dificuldade no consórcio, porque teve eleição ano passado, ai teve alguns prefeitos que não foram reeleitos e já estavam incluido no consórcio, ai teve prefeitos que foram eleitos agora, recentemente, ai teve que ter aquela adaptação, aí realmente ver se, porque a questão não é necessidade, é obrigação agora que vai ter que acabar com os lixões nos municípios. " (AP10)

"Então o que está se fazendo, está se fazendo um consórcio, porque dentro dos programas hoje, como é feito o aterro sanitário, o município não tem como arcar. Aí você faz: como não tem como arcar? O problema que as rendas do município estão voltadas para praticamente, folha, combustivel e remédio, esses três pilares. $O$ dinheiro da prefeitura vem e sobra muito pouco e isso é um investimento de grande porte, e o município não tem condição. ” (AP12)

Nas cidades estudadas, ainda há muitos desafios em relação à implantação e manutenção dos aterros. Em Alagoa Grande o aterro foi instalado por volta de 2008, mas está sem funcionamento tanto pela descontinuidade política como também pela falta de recursos e in- 
fraestrutura, além do declínio de adesão da população ao programa de coleta seletiva que fora desenvolvido. Bananeiras, Solânea e Guarabira estão envolvidas na construção do aterro através de um consórcio intermunicipal, que é dificultado devido a opiniões diversas. Em Dona Inês, as instalações foram iniciadas dentro das regulamentações exigidas, porém, a obra se mantém parada. A única cidade cujo aterro está em funcionamento, aponta que a prática está divergindo do plano de resíduos, já que o lixo é encaminhado, em sua totalidade, para o aterro sanitário, não havendo separação ou qualquer tratamento prévio, implicando em alto custo de manutenção e menor durabilidade do aterro.

"É como eu disse a você, fizeram uma lei muito boa, só que esqueceram da realidade do município. Vai ter condição de cumprir? Não tinha condição de cumprir. Porque não tinha o dinheiro para fazer o aterro, então a única solução foi fazer cooperativa e um aterro participativo de todos os municípios." (AP12)

É, ... aqui a gente tem um problema sério, de que, o que a gente arrecada de taxa ou limpeza não dá para pagar 2 meses dos gastos. Tem que melhorar isso aí, gasta-se 3,5 milhões com varrição, coleta, aterro em torno de 2 milhões. Não o bastante, se você fizer per capita tonelada por habitante a gente está gastando 4,68,é um dos melhores do Brasil. " (AP9)

Com isso, compreende que o lixo deveria ser selecionado a fim de ocupar menos espaço possível dentro desses aterros, uma vez que, com a disposição total dos resíduos pode vir a ocorrer uma diminuição no tempo útil real do aterro sanitário.

"A cada oito meses, já precisa de outra célula, porque lá é colocado tudo. Agora, se fosse só o rejeito, se houvesse a reciclagem, a ideia seria de oito anos, no mínimo seria essa relação, veja como e importante né essa questão da reciclagem, ela é fundamental, infelizmente os municípios, não, lamentavelmente eles não são preparados para isso, às pessoas não são preparadas para isso, a nossa cidade aqui, por exemplo, nossos distritos são cheios de lixo que as pessoas jogam, as escolas parecem que não dão conta de educar" (AP3)

Enquanto o Brasil discute o fim dos lixões, em outros países do mundo a discussão se amplia para o debate sobre o descarte e a reciclagem, muitos gestores têm ideia das políticas adotadas em outros países. Como apontam os discursos dos agentes públicos, há o reconhecimento de que a população cumpre um papel fundamental na governança do lixo em outros países.

"A Itália tem casos parecidos com aqui, uma realidade mais próxima, mas já a Alemanha, já é outra dimensão. A boa tendência é o aterro evoluir para uma usina de lixo, já tivemos várias propostas aqui, mas quando eles chegam falando as propostas a gente começa a quantificar... É complicado! A pessoa pede para mostrar em algum lugar que funciona, mas não tem, não tem 
não. Tão falando que tem na Alemanha, na Itália. Mas olha a realidade né? " (AP9)

A fala supracitada remete à necessidade de construção de uma consciência ambiental, que está sendo negligenciada como uma ação eficiente para a consolidação da política nacional de resíduos sólidos nos municípios. Além disso, os agentes públicos entendem que é preciso uma ação combinada com outros agentes interessados no lixo, como as associações de catadores e as cooperativas de reciclagem. Corroborando com Baptista (2013) o qual aponta que as políticas e ações relacionadas a gestão de resíduos devem ser inclusivas em relação a possíveis benefícios e integrativas em relação a instituições e atores.

"Claro, isso aí é um... porque primeiro a consciência das pessoas, primeiro você vai ter aquela consciência de que precisamos reciclar, vamos supor, latinha, plástico, tudo que for reciclável, né? Então primeiro a consciência das pessoas, quer dizer, essa lei veio trazer que as pessoas têm que se organizar, porque isso é o futuro. Porque imagine, essa quantidade de plásticos hoje que você insere na natureza? " (AP12)

"Ai a gente pensa em incluir que eles também têm uma associação, só que está desativada, aí a gente vai dar um suporte logístico, jurídico também, o prefeito colocou, pediu para colocarem, essa associação em funcionamento, até para adquirir linhas de crédito, você sabe também que vai ter, os bancos têm interesse de fazer financiamento de cooperativas, ou associação de catadores, e também eles querem ajudar no sentido ao bom funcionamento da coleta seletiva, separação do lixo". AP10

"Não adianta só investir lá no destino final, você precisa tirar antes, por que você está beneficiando uma cadeia produtiva antes, né!? E daí você aterra menos, é mais barato para o próprio município, mas está indo tudo ao contrário por conta de que não está sendo cumprido o que está previsto no plano. " (AP7)

Nesse sentido, emergiu durante as entrevistas um debate sobre a coleta seletiva, muitos dos agentes reforçaram o entendimento de que é preciso uma interação mais ampla entre a gestão do lixo e a população para que o investimento no aterro sanitário seja duradouro e eficaz. Tal percepção se vocaciona como uma questão de marketing social, na medida em que consiste em definir estratégias para combater os problemas de impacto social, no sentido de transformar as motivações e desejos dos indivíduos e promover o bem-estar e a qualidade de vida (STEAD et al, 2007).

"Precisa de mais conhecimento, eu acho que tem que ter um trabalho, tem que envolver, começar a envolver a secretaria de educação, porque tudo parte do princípio que você educando aquele jovem que está lá na escola ele vai transferir para os pais, entendeu? Aquela realidade dizer: vamos separar o plástico, vamos separar o vidro, né? Se quebra um negócio, não joga dentro do lixo, porque já aconteceu no passado de garis levar cortes aqui na pegada do lixo doméstico. "(AP12) 
Ainda dentro do escopo de marketing social, muitas das falas dos agentes públicos enxergaram uma necessidade de discussão de medidas punitivas para complementar as ações de conscientização.

"Porque se a população não fizer sua parte, infelizmente, o município pode fazer campanhas educativas, investir em publicidade, mas se a população não tiver aquela conscientização de que não está ajudando o prefeito, eu estou ajudando a minha cidade, de colocar o lixo, de separar, de ajudar na coleta seletiva a gente não vai vencer nunca essa guerra. Por mais que o município invista, isso é questão financeira, e a população vai se conscientizar disso, porque hoje a gente não pretende incluir a taxa de lixo, mas quem sabe no futuro, vai ter que ter, vai chegar um ponto de o município dizer, ou eu deixo as escolas funcionando e os postos de saúdes, e a limpeza pública de varrição, de coleta, ou eu vou colocar todo o recurso do município para manter o aterro. Cidade limpa é compromisso de todos. ". (AP10)

"Eu acho importante à punitiva. O povo só aprende quando dói no bolso. A gente vê tranquilo aqui" (AP2).

A partir dos achados da pesquisa é possível dizer que das cidades estudadas, Campina Grande é a única que possuía aterro em funcionamento até a realização das entrevistas. O aterro da cidade está em funcionamento há cerca de dois anos, atendendo em sua maior parte a região metropolitana. Entretanto, as práticas de gerenciamento do aterro diferem do papel do Plano de Resíduos Sólidos, já que o lixo está indo em sua totalidade, sem separação do que poderia ser reciclado e do que já não é mais aproveitável, implicando diretamente em um alto custo de manutenção do aterro e consequentemente na durabilidade do mesmo. A cidade de Alagoa Grande foi a primeira entre as estudadas a refletir e implementar a criação do aterro, mas não conseguiu manter o funcionamento, devido principalmente a descontinuidade política, falta de colaboração da população e condições ambientais legais.

Em Dona Inês a obra do aterro foi iniciada em 2016, em uma área dentro das especificidades legais, porém não foi concluída, devido à descontinuidade política. As demais cidades: Bananeiras, Solânea e Guarabira engatinham para buscar as instalações do aterro através de um consórcio intermunicipal visando uma captação maior de recursos. As discussões desse consórcio intermunicipal envolvendo os municípios citados deu uma estagnada em relação às reuniões, devido ao resultado das eleições de 2016, onde muitos prefeitos não podiam mais se reeleger, e os candidatos indicados por eles não venceram as eleições, resultando em um processo de adaptação às leis e as discussões fomentadas pelo consórcio para a construção do aterro.

Portanto, é preciso empreender esforços de educação, conscientização e marketing social em larga escala, uma vez que a participação da população e adesão aos programas de coleta seletiva e reciclagem é a base de qualquer plano de resíduos sólidos bem-sucedido. Os esforços educacionais devem ser diversificados e difundidos nas escolas, 
famílias e comunidade, com o objetivo de gerar coesão entre os atores que executam a política pública em torno do lixo. Tais resultados corroboram os apontamentos da literatura, na medida em que reforçam a visão de que os recursos direcionados ao gerenciamento do lixo são em grande medida desperdício de dinheiro público e de esforços da gestão (MONTEIRO, 2001). Por outro lado, é possível que essas dificuldades sejam superadas pela aplicação de políticas de gestão que prezem por soluções de baixo custo e alto impacto como têm se apresentado as ações de marketing social.

\section{CONSIDERAÇÕES FINAIS}

O objetivo desse estudo foi analisar a percepção e a interlocução dos agentes públicos municipais na governança do lixo e no processo de instalação do aterro sanitário. Os resultados apresentados nos itens anteriores apontam para a realização desse objetivo. De maneira geral, os resultados apontam para o desafio das instalações e manutenção dos aterros sanitários dos seis municípios estudados, que são decorrentes de três fatores principais: a descontinuidade política, a escassez de recursos e a falta de colaboração da população.

Em termos de governança do lixo, a descontinuidade política é um fator de extrema relevância, pois a transição dos gestores municipais implica sobremaneira nos projetos da gestão passada, sendo priorizado o plano da gestão atual, que muitas vezes destoa em termos de prioridades, sobressaindo interesses individuais do gestor, como o voto, por exemplo. A legislação da Política Nacional de Resíduos Sólidos cobra a consecução ampla dos objetivos previstos, porém, em contrapartida os municípios de pequeno porte não têm recursos financeiros e administrativos próprios suficientes destinados pela entidade federal para realização da política pública. A escassez de recursos também afeta o investimento em capacitação dos profissionais em esfera pública, mantendo uma capacidade de gerenciamento dos resíduos muito baixa. Por fim, a população dá pouca importância ao lixo, se preocupando apenas em tirar o lixo da vista, não se importando com o descarte final.

A pesquisa contribui do ponto de vista teórico e prático, na medida em que analisa como os atores de diferentes municípios de uma mesma região estão atuando para a execução da Política Nacional de resíduos sólidos, principalmente, na implantação dos aterros sanitários. $\mathrm{O}$ artigo ressalta exemplos de cidades que conseguiram suplantar a exigência do aterro, mas que enfrentam dificuldades na sensibilização da população acerca do seu papel na política pública. Por outro lado, aponta um conjunto de problemas que atingem quase que a maioria dos municípios brasileiros.

Dessa forma, o estudo serve de referência tanto em pesquisas que busquem analisar a governança do lixo em municípios de médio e pequeno porte, como também para estudos que se encaminhem a compreender aspectos que influenciam a população a aderir a programas de coleta seletiva do lixo e reciclagem. Ademais, a pesquisa tangenciou 
o papel das associações e cooperativas de catadores como agente interessado na discussão dos aterros sanitários.

Embora as técnicas utilizadas e os procedimentos de campo tenham sido as que comumente se utilizam em estudos do mesmo tipo, a pesquisa teve as limitações decorrentes do processo de pesquisa qualitativa, que demandou adequação de tempo para os entrevistados, além da ausência de padronização. Adicionalmente, são sugeridos estudos futuros que analisem a situação da implementação dos aterros sanitários em outros municípios, como também, que estudem de forma mais aprofundada as relações de governança do lixo e os arranjos institucionais derivados dos aterros sanitários e da Política nacional de resíduos sólidos, além de estudos em marketing social.

\section{REFERÊNCIAS}

ABNT, A. NBR 8419 - Apresentação de projetos de aterros sanitários de resíduos sólidos urbanos. Associação Brasileira de Normas e Técnicas, 1983.

ABRELPE. Panorama Dos Resíduos Sólidos No Brasil, Associação Brasileira das Empresas de Limpeza Pública e Resíduos Especiais. 2015. Disponível em: <http://www.abrelpe. org.br/Panorama/panorama2015.pdf>. Acesso 31 de Maio, 2013.

Baptista, Vinícius Ferreira. “Liberdade pelo trabalho ou trabalho pela liberdade?-O caso dos catadores de materiais recicláveis." Revista Brasileira de Políticas Públicas 3.1 (2013).

BARDIN, L. Análise de conteúdo. Lisboa: Edições 70, 2007.

CHAVES, Gisele de Lorena Diniz; BATALHA, Mário Otávio. Os consumidores valorizam a coleta de embalagens recicláveis? Um estudo de caso da logística reversa em uma rede de hipermercados. Gestão \& Produção, v. 13, n. 3, p. 423-434, 2006.

de Oliveira Estevam, Dimas. "A contínua descontinuidade administrativa e de políticas públicas." Seminário de Ciências Sociais Aplicadas 2.2 (2010).

EZEAH, Chukwunonye; ROBERTS, Clive L. Waste governance agenda in Nigerian cities: A comparative analysis. Habitat international, v. 41, p. 121-128, 2014.

FINKELSTEIN, Lawrence S. "What is Glboal Governance”. Associação de Estudos Internacionais, Vancouver, 1991. pp. 367-372.

FREY, Klaus. Artigo: Governança interativa: uma concepção para compreender a gestão pública participativa?. Política \& Sociedade, v. 3, n. 5, p. 118-138, 2004. 
GAZZINELLI, Maria Flávia et al. Educação e participação dos atores sociais no desenvolvimento de modelo de gestão do lixo em zona rural em Minas Gerais. Educação e Sociedade, v. 22, n. 74, p. 225-241, 2001.

GODOY, Arilda Schmidt. Estudo de caso qualitativo. Pesquisa qualitativa em estudos organizacionais: paradigmas, estratégias e métodos. São Paulo: Saraiva, p. 115-146, 2006.

HALL, A. Una gobernabilidad eficaz para el agua: Documento base para el Diálogo Global Water Patterneship-GWP. Abril, 2002.

HENN, Sara A.; CASAGRANDE, Jacir L.; NUNES, Nei A.; LEITE, André L. da S.; PICOLLI, Ícaro. Planejamento estratégico de uma instituição de ensino superior federal brasileira: uma análise à luz do movimento da governança pública. Organizações em contexto, São Bernardo do Campo. vol. 13, n. 25, p. 219-243. 2017.

HIRD, Myra J. et al. Making waste management public (or falling back to sleep). Social Studies of Science, v. 44, n. 3, p. 441-465, 2014.

HOWELL, Jordan P. Waste governance and ecological identity in Maui, Hawaii, USA. Geoforum, v. 79, p. 81-89, 2017.

IBÁÑEZ-FORÉS, Valeria et al. Temporal evolution of the environmental performance of implementing selective collection in municipal waste management systems in developing countries: A Brazilian case study. Waste Management, v. 72, p. 65-77, 2018.

IBGE. Pesquisa Nacional de Saneamento Básico. 2010. Disponível em <https://biblioteca.ibge.gov.br/visualizacao/ livros/liv45351.pdf $>$. Acesso em 09 de mai. 2018.

JACCOUD, C.; MAGRINI, A. Regulation of solid waste management at Brazilian ports: Analysis and proposals for Brazil in light of the European experience. Marine pollution bulletin, v. 79, n. 1-2, p. 245-253, 2014.

KISSLER, L.; HEIDEMANN, F. Governança pública: novo modelo regulatório para as relações entre Estado, mercado e sociedade?. Revista de Administração Pública, v. 40, n. 3, p. 479-499, 2006.

KRASNIQI, Ibrahim; KRASNIQI, D.; KRASNIQI, G. Strategic Local Governance Policy and Waste Management-Prishtina Municipality Case. IFAC Proceedings Volumes, v. 46, n. 8, p. 176-180, 2013. 
LIMA, L. F; FILHO, R. G. Governança das parcerias públicoprivadas: dimensões analíticas e proposições. São Paulo. 2017.

LIMA, P. G. et al. Avaliação de um aterro sanitário por meio do índice de qualidade de resíduos sólidos/Evaluation of solid waste in a landfill by means of the quality index. Revista Brasileira de Engenharia de Biossistemas, v. 11, n. 1, p. 88-106, 2017.

LINDQVIST, Katja. Hybrid governance: the case of household solid waste management in Sweden. Public Organization Review, v. 13, n. 2, p. 143-154, 2013.

MALINAUSKAITE, J. et al. Municipal solid waste management and waste-to-energy in the context of a circular economy and energy recycling in Europe. energy, v. 141, p. 2013-2044, 2017.

MONTEIRO, J.H.P. et al. Manual de Gerenciamento Integrado de Resíduos Sólidos. Rio de Janeiro: IBAM, 2001.

MORAES, R. Análise de conteúdo. Revista Educação, Porto Alegre, v. 22, n. 37, p. 7-32, 1999.

MÜHLE, S.; BALSAM, I.; CHEESEMAN, C. R. Comparison of carbon emissions associated with municipal solid waste management in Germany and the UK. Resources, Conservation and Recycling, v. 54, n. 11, p. 793-801, 2010.

NAIME, R; VON MENGDEN, P. R. A. Diagnóstico de gestão otimizada do sistema de resíduos sólidos domésticos e comerciais do município de TaquaraRS. Planejamento e Políticas públicas, n. 30, Brasília: Instituto de Pesquisa Econômica Aplicada, 2007.

NARUO, Mauro Kenji. O estudo do consórcio entre municípios de pequeno porte para disposição final de resíduos sólidos urbanos utilizando sistema de informações geográficas. 2003. Tese de Doutorado. Universidade de São Paulo.

OLIVEIRA, A. Método Para a Viabilização da Implantação de Plano de Gerenciamento Integrado de Resíduos Sólidos: O Caso do Município do Rio Grande - RS. Tese de Doutorado, Universidade Federal de Santa Catarina, Programa de Pós-Graduação em Engenharia de Produção da Universidade Federal de Santa Catarina, Florianópolis, 2002.

OLIVEIRA, Cristiane de Fátima. Reciclagem dos Resíduos

Sólidos: Atitude essencial para a sobrevivência do planeta/ Cristiane de Fátima Oliveira. FEMA: Fundação Educacional do Município de Assis - Assis, 2013.

ONU. Organização das Nações Unidas. 2009. 
Disponível em https://nacoesunidas.org/acao/ governanca/. Acesso em 19 de maio 2019.

OWUSU, George; OTENG-ABABIO, Martin; AFUTUKOTEY, Robert L. Conflicts and governance of landfills in a developing country city, Accra. Landscape and Urban Planning, v. 104, n. 1, p. 105-113, 2012.

RAMOS, Silma Pacheco. A Lei da Política Nacional de Resíduos Sólidos e a meta de implantação de aterros sanitários no Brasil. In: Âmbito Jurídico, Rio Grande, XVII, n. 121, fev 2014. Disponível em: <http://ambito-juridico. com.br/site/?n_link=revista_artigos_leitura\&artigo_ id=14280\&revista_caderno=5>. Acesso em mai 2018.

ROY, Dilip Kumar. Governance, Competitiveness, and Growth: The Challenges for Bangladesh. 2006.

STEAD, M.; HASTINGS, G.; MCDERMOTT, L. The meaning, effectiveness and future of social marketing. Obesity Reviews, v. 8, p. 189-193, 2007.

WALDMAN, Maurício. Reciclagem, catadores e gestão do lixo: dilemas e contradições na disputa pelo que sobra. Boletim Paulista de Geografia, n. 93, p. 131-145, 2013.

ZHANG, Dong Qing; TAN, Soon Keat; GERSBERG, Richard M. Municipal solid waste management in China: status, problems and challenges. Journal of environmental management, v. 91, n. 8, p. 1623-1633, 2010. 